\title{
O CONTO POLICIAL E AS ORIGENS DA PSICANÁLISE
}

\author{
Prado de Oliveira* \\ Tradução de Patrick Charles Wuillaume
}

RESUMO

A lenda de Édipo é a primeira aventura "policial” de nossa história e uma das mais modernas: um homem busca um assassino sem saber que é, ele próprio, este assassino. Freud ignora Sherlock Holmes, mas é para este que a reflexão ideal exige luz baixa e se recostar em um divã. Alguns contos de Edgar Allan Poe se tornaram passagens obrigatórias do pensamento psicanalítico francês, não sem problemas. Desde os primeiros estudos de Freud sobre Leonardo Da Vinci, a psicanálise aplicada sempre encontrou dificuldades, que talvez não sejam estranhas à técnica psicanalítica individual. Este artigo as examina.

Palavras-chave: a Carta roubada; Poe; Lacan; Derrida; Édipo.

\section{Abstract}

\section{THE MYSTERY NOVEL AND THE ORIGINS OF PSYCHOANALYSIS}

The myth of Oedipus is the first "mystery" adventure of our time and one of the most modern: a man searches for a murderer without knowing that he himself is the criminal. Freud ignores Sherlock Holmes, but this is the one that an ideal reflection requires a dim light and a couch. Some stories by Edgar Allan Poe have become required passages in French psychoanalytic thought, not without some trouble. Since Freud's first studies on Leonardo Da Vinci, applied psychoanalysis has always encountered difficulties that may not be so different from the ones faced by individual psychoanalytic technique. This article examines them.

Keywords: the Purloined letter; Poe; Lacan; Derrida; Oedipus.

* Professor do Departamento de Psicologia da Faculdade Victor Segalen, Universidade Europeia da Bretanha Ocidental; Diretor de Pesquisas da Escola Doutoral Pesquisas em Psicopatologia e Psicanálise, Universidade de Paris 7 - Denis Diderot; Membro psicanalista de Espaço Analítico. 
"A carta roubada" é um conto de Edgar Allan Poe, de 1844 (2004). Esse conto não teria tido toda a importância que teve para a psicanálise se Lacan não tivesse se valido dele como parábola de um conjunto de suas próprias teses.

Nesse conto, o detetive Auguste Dupin é informado por G..., Chefe de Polícia de Paris, que uma carta da maior importância fora roubada no toucador real. O policial sabe quem roubou e precisamente quando o fez, mas está impossibilitado de acusar o culpado. Apesar de minuciosas buscas feitas no domicílio do ladrão, G... não encontrara a carta, cuja recuperação é importantíssima, pois o ladrão pode vir a pressionar o membro da família real de quem a roubou. G... vem portanto solicitar o auxílio de Dupin. Algumas semanas mais tarde, este restitui a carta ao Chefe de Polícia. E explica então ao narrador como alguns princípios singelos lhe permitiram encontrar a carta.

Antes de Lacan, outros psicanalistas já se haviam interessado por Poe. Krutch, em 1926, havia detectado sinais da impotência sexual em sua vida e obra, Marie Bonaparte, em 1933, ali descobriu um caso exemplar de complexo de Édipo, acrescido de tendências sadonecrofílicas. A descoberta do papel desempenhado pelo narrador, criado pelo autor e dele diferente, é recente. Mas a tendência geral é fazer de Poe um "genial impostor", vocábulo moderno que expressa o que ele próprio chamava de "faculdade de identificação".

Baudelaire torna Poe célebre na França, e essa celebridade ecoa na literatura mundial. Mallarmé e Valery descobrem, por sua vez, o poeta e filósofo. Todos os simbolistas, numerosos autores realistas de contos, os surrealistas e os teóricos do novo romance homenageiam o autor cuja influência sobre a literatura europeia é ainda matéria de estudo e rica de ensinamentos insuspeitados (Richard, 2007).

Todos esses resumos, porém, não permitem compreender o interesse desta novela particular para os psicanalistas. O que lhes interessa, parece-me, é que os personagens de Poe mantêm conversas que são verdadeiras dissertações filosóficas, epistemológicas e metodológicas. Um exemplo, desde as primeiras linhas do "Duplo assassinato na Rua Morgue": "As faculdades do espírito que definimos por meio do termo analíticas são em si mesmas muito pouco suscetíveis de análise. Só as apreciamos por seus resultados". E pouco além: "Contesto a validade e consequentemente os resultados de uma razão cultivada através de qualquer processo que não seja a lógica abstrata. Contesto muito especialmente o raciocínio que decorre do estudo da matemática". E "O grande erro consiste em supor que aquilo que é chamado de puramente algébrico são verdades abstratas ou gerais... Os axiomas matemáticos não são axiomas de uma verdade geral". Sobretudo: "O que é verdadeiro numa relação de forma ou de quantidade constitui muitas vezes um erro grosseiro sob o ângulo da moral, por exemplo. E nessa última ciência é 
muitas vezes falso afirmar que a soma dos fatores é igual ao total" (Poe, [1841] 2004: 47).

Foram essas considerações que atraíram a atenção dos psicanalistas para essa novela de Poe. Expressam uma noção revolucionária e curiosa: a moral seria uma ciência em pé de igualdade com a matemática, por exemplo. Essa noção é a fonte da noção lacaniana segundo a qual a ética, ou o que ele considera como sendo ética, muito diferente do que considera Aristóteles de maneira inaugural, por exemplo, tem uma relação íntima com a psicanálise, considerada como uma ciência, no mesmo nível que as ciências exatas.

Encontramos em Poe o que aparecerá quase um século depois, com Gödel, como o "teorema da incompletude" e seus corolários. Cumpre assinalar, entretanto, que as teses de Poe nestes contos não possuem nem uma estabilidade e nem uma coerência incontestáveis, o que transparece em sua comparação entre os jogos de damas e o xadrez, quer dizer, sua comparação entre um jogo com número de variáveis bem definidas e limitadas e um jogo mais complexo, com número de variáveis bem maior e possibilidades infinitas.

O dossiê que apresento contém as contribuiçōes mais importantes feitas em relação à "Carta roubada". Comento-as e concluo com minhas próprias observações.

\section{LACAN}

O curso sobre a "Carta roubada", pronunciado em 26 de abril de 1955, no seminário $O$ eu na teoria de Freud e na técnica da psicanálise, foi inicialmente publicado numa versão reescrita entre maio e agosto de 1956 , na revista $L a$ psychanalyse no 2, 1957, páginas 15-44, precedido de uma Introdução, às paginas $1-14$.

Lacan introduz esse curso através de considerações sobre o jogo do "par ou ímpar”. Duas crianças brincam disso. Uma delas ganha mais vezes do que a outra, embora a estatística nos leve a crer que cada um delas tem possibilidades iguais. Deduzir-se-á, mais tarde, que se tratava de considerações sobre a transferência e a contratransferência.

A leitura da "Carta roubada" abre também os Escritos de Lacan ([1949] 1966) e constitui para ele oportunidade de apresentar seu esquema L, um dos pilares de sua teoria. Esse esquema $\mathrm{L}$ articula, nas suas quatro extremidades, o $S$ ( $E$ s, id ou "s" de sujeito, ou sujeito do inconsciente), o pequeno outro, a', o ego, a, e o grande Outro. Esse esquema é diferente do esquema $\mathrm{R}$, ulterior, e ainda do esquema I. $\mathrm{O}$ esquema $\mathrm{R}$, como real ou realidade, torna mais complexo o esquema $\mathrm{L}$ e o esque- 
ma I, como imaginário, é suposto explicar a psicose, ou, em todo caso, a psicose de Schreber (Freud, [1911a] 1969).

O conto de Poe é, assim, um pretexto para Lacan, que extrai dali duas cenas, quatro ou cinco personagens. A primeira, em que um Ministro, D., entra no apartamento real no momento em que a Rainha lê uma carta e que o Rei está distraído. A Rainha coloca na mesa a carta que lia, com indiferença. O Ministro olha a Rainha, que olha o Rei, que não olha nada. O Ministro escreve rapidamente uma outra carta, coloca-a junto à primeira e apanha esta última. A Rainha se vê na impossibilidade de intervir para não atrair a atenção do Rei. Estes são, para Lacan, os três tempos lógicos da constituição da intersubjetividade e da verdade, cuja chave é a identificação. A criança que ganha com mais frequência no jogo do par ou ímpar é a criança que se identifica à outra e, logo, antecipa o que ela jogará. Na ocorrência, D. se identificou à Rainha e ao Rei, pareceria.

Lacan faz menção também à visita do Chefe de Polícia ao apartamento do Ministro para tentar recuperar a carta, a seu insucesso, seu recurso a Dupin; a primeira visita desse detetive ao apartamento do Ministro, quando encontra a carta bem à vista, tal como tinha estado também à vista no apartamento real - já que a Rainha não tinha realmente procurado escondê-la, o que lhe teria sido bem fácil. Lacan menciona ainda a segunda visita de Dupin ao apartamento do Ministro, a astúcia que emprega para recuperar a carta, astúcia essa que distrai o Ministro, como antes o Rei também se distraíra, e, enfim, a manobra idêntica àquela do Ministro junto à Rainha, ou seja a substituição da carta por uma outra, semelhante, e, finalmente, a devolução da carta original à Rainha. Se Dupin consegue achar a carta roubada é devido à sua capacidade de se identificar ao Ministro e, logo, adivinhar onde ele esconderia a dita carta.

Lacan é muito criativo, genial mesmo, mas não é um exegeta nem de Poe nem de Freud, nem aliás da psicanálise, da filosofia ou da linguística. Seu texto sobre o conto de Poe data de 1955-1956. Será preciso esperar cerca de vinte anos para que um filósofo sacuda os analistas, siderados diante da excelência teórica e analítica de Lacan.

\section{Derrida}

No "Le facteur de la vérité", que tanto pode ser traduzido como O fator $d a$ verdade ou $O$ carteiro da verdade, Derrida ([1975] 1987) assinala um ponto interessante: com muita frequência as citações de Freud parecem ser feitas de segunda mão. Freud cita Keller que cita Homero, Freud cita Fulda que cita Andersen e assim por diante. Derrida deduz daí que a narrativa literária é uma 
elaboração secundária. E traz uma precisão: o seminário sobre a carta roubada foi pronunciado em 1955, escrito em 1956, publicado em 1957 e colocado em 1966 no cabeçalho dos Escritos (Lacan, [1949] 1966). É como se Lacan estivesse citando a si próprio três vezes, reproduzindo o ato de citação freudiano, incluindo seu texto sobre a carta roubada em uma reflexão mais ampla sobre o automatismo de repetição.

Ao fazê-lo, porém, Lacan esquece a história, embora a palavra "história" apareça quatro vezes nas duas primeiras páginas de seu texto. E cria uma oscilação entre verdade e ficção. A verdade pode habitar a ficção. E Derrida ([1975] 1987) se interroga sobre a interrogação lacaniana a respeito do caráter fictício da verdade e a do caráter verdadeiro da ficção. E chega mesmo a duvidar do sentido dessa pergunta.

As perguntas e desenvolvimentos de Derrida ([1975] 1987) trazem diferentes eixos de reflexão. Em essência, Derrida assinala que a redução por Lacan do conto de Poe a duas cenas, cada uma delas baseada numa estrutura triangular, sendo a segunda um desdobramento da primeira, implica a exclusão radical do personagem do narrador. Com efeito, parece-nos bastante surpreendente hoje, seja qual for o ponto de vista adotado, que Lacan possa dizer do narrador - "que este não acrescenta nada”. No conto de Poe, o narrador não é o autor. Poe cria um personagem que narra, ao invés de narrar ele próprio.

A inclusão da existência do narrador na análise do conto tem uma implicação imediata: a estrutura das cenas não é mais ternária, mas sim quaternária. E a lógica da carta de Lacan, implicando que a carta chega sempre ao seu destinatário, desaparece, pois existem cartas que nunca foram recebidas, sem que se saiba onde chegaram, e sem que por isso estejam em espera (en souffrance, em francês: diz-se de uma carta que não foi entregue que ela sofre, da mesma maneira que um morto que não foi honrado vira alma penada); outras cartas nem mesmo foram postas no correio, e são esquecidas. Outras, ainda, chegam sem que se conheça seu exato percurso. São minhas primeiras observações.

Com efeito, a crítica de Derrida ([1975] 1987) a Lacan me parece discreta a respeito do destino das cartas, pois o filósofo limita-se a contradizer a afirmação de Lacan, opondo a esta afirmação o fato evidente de que uma carta pode não chegar ao seu destinatário.

Derrida ([1975] 1987) acrescenta ainda que "A carta roubada" não é o título de um objeto do qual fala um conto, mas sim o título do próprio conto. Nesse sentido, para ele, nenhuma carta chega verdadeiramente ao seu destino e, quando chega, a possibilidade de que não chegue a perturba, como se houvesse um desvio interno que lhe é consubstancial. É o que todo epistolário e toda correspondência 
assídua confirmam amplamente: as cartas que mandamos não são nunca totalmente as que nossos correspondentes leem e aquelas que recebemos não são nunca totalmente aquelas que nos foram destinadas. Aliás, o mesmo se aplica a toda forma de comunicação, inclusive intrassistêmica, acrescento.

Uma vez chegado ao seu primeiro ponto de contestação das teses de Lacan, Derrida ([1975] 1987) abre várias pistas, que, em verdade, acaba não seguindo até o fim.

Inicialmente, abre a pista da crítica do "falogocentrismo" e, assim, critica o papel atribuído por Lacan ao falo como significante primordial. O "falogocentrismo" de Lacan se apoiaria no falicismo de Freud, segundo Derrida ([1975] 1987), que esquece as matizes introduzidas por Freud no seu falicismo, notadamente em textos como "Grande é a Diana dos Efésios" (Freud, [1911b] 1969) ou suas notas de rodapé do texto sobre "A sexualidade feminina" (Freud, [1931] 1969). Aliás, existem também nuances introduzidas por Lacan com relação às suas próprias teses, como a importância do desejo da mulher na constituição do falo enquanto tal. Guignard (1996), em seu belo livro Le sexe et l'effroi, traz precisões sobre a noção de falo que o afastam definitivamente de toda conotação peniana exclusiva. Pode-se contrapor a Derrida também o fato de que Lacan não atribui um campo preciso à linguagem: seria ela palavra, seria ela escrita ou semiótica, todas estas alternativas ao mesmo tempo, ou seja talvez alguma coisa a mais? Os próprios linguistas não parecem tampouco fazê-lo. Entre os psicanalistas de orientação lacaniana, de início, uns e outros privilegiaram uma ou outra abordagem da linguagem, produzindo o que, se não me engano, Octave Mannoni chamou de "linguisteria", quer dizer, o simulacro de linguística aplicada à psicanálise em torno do conceito de significante, linguística que perde todo o sentido caso não esteja integrada a uma teoria geral dos signos, ou seja, a uma semiótica, integração mais tarde promovida por Kristeva.

Em segundo lugar, Derrida ([1975] 1987) assinala com justa razão, mas sem prosseguir nesta via, o esquecimento por Lacan dos textos da Princesa Marie Bonaparte sobre Poe, estudos que trazem uma bela introdução de Freud, ao mesmo tempo que ele, Derrida, critica tanto a Princesa quanto Lacan, por se basearem ambos em estruturas triangulares na abordagem das novelas de Poe.

Em terceiro lugar, Derrida ([1975] 1987) inaugura a compreensão da "Carta roubada”, enquanto um dos elementos de uma trilogia na qual os dois outros contos são "O duplo assassinato da Rua Morgue" ([1841] 2004), primeiramente, e "O mistério de Maria Roget" ([1842] 2003), a seguir. Mas Derrida não para tampouco por aí. 
Isto porque a revelação do papel do narrador lhe permite mostrar com facilidade como as duas cenas isoladas por Lacan são fictícias e que "A carta roubada" de Poe corresponde a uma multiplicidade de narrações: Poe conta que um amigo de Dupin contou, que Dupin contou... todas as aventuras que lemos. E até mesmo a expressão "um destino tão funesto..." que serve de epígrafe ao texto de Lacan, e que teria sido escrito por Dupin, na carta que deixa ao alcance do Ministro para melhor enganá-lo, e que lhe serve assim, digamos, como sua assinatura, essa epígrafe não é aquela que figura no texto de Poe. Esta última, com efeito, reza: Nil sapientiae odiosius acumine nimio, frase que Poe atribui a Sêneca e que nenhum pesquisador foi capaz de encontrar nos escritos desse autor. "Nada, em matéria de sabedoria (ou de sapiência), é mais detestável do que a sutileza excessiva" (Poe, [1844] 2004: 92), diz a epígrafe de Poe a seu conto.

O que deveria ter bastado para que nem Lacan, nem Derrida, nem ninguém tentasse prosseguir a análise do conto de Poe, que, por assim dizer, desautoriza seu próprio personagem, Dupin. Deve haver alguma boa dose de histeria dos psicanalistas. Quando são avisados que não adianta continuar, é aí que insistem. Na clínica, como na teoria. Isto em si mesmo constitui um filão da história da psicanálise.

Esse verdadeiro arsenal teórico construído por Derrida ([1975] 1987) servelhe para atacar o conjunto da obra de Lacan. E por que não o faria? Já, em oportunidades anteriores, Derrida queixara-se da extrema agressividade de Lacan a seu respeito. E eu mesmo, pessoalmente, tenho queixas contra a extrema agressividade de Derrida a meu respeito por ocasião do encontro franco-britânico de Brighton em 1981. Voltarei também a falar sobre o papel e a importância dessas considerações pessoais. Mas, seja como for, o texto de Lacan serve de pretexto a Derrida, da mesma forma que o de Poe serve a Lacan.

\section{RUMORES AMERICANOS}

A cada vez que falamos de geometria - e aqui trata-se da discussão sobre a estrutura ternária ou quaternária da novela de Poe - a aritmética não se encontra longe. Como são obtidas as estruturas? A estrutura ternária pode ser obtida a partir de um cálculo de $2+1$, e a estrutura quaternária a partir de um cálculo de $2+2$, ou seja, por exemplo, as duas cenas em que uma duplica a outra, ou então a partir de um cálculo de $3+1$, a saber, os três personagens presentes na primeira cena, aos quais se soma o narrador. $2+1$ equivaleria aos dois personagens da reale$\mathrm{za}$, nos seus apartamentos, aos quais vem se acrescentar o Ministro. E mesmo Dupin não tem como agir sozinho para recuperar a carta na casa do Ministro: um 
policial o ajuda, desencadeando cena barulhenta sob a janela do dito Ministro, que corre para vê-la, esquecendo por um instante a presença de Dupin no aposento. Claro que todas estas cenas podem obedecer à uma aritmética de $1+1+1+1+1$, indefinidamente. É o que discute Lacan em seu seminário. Na ocorrência, imagino, 1 corresponderia à aritmética do narcisismo.

Poderíamos objetar que a segunda cena não duplica perfeitamente a primeira e que essa duplicação é uma construção lacaniana que não leva em consideração o texto de Poe. Um único elemento se repete de uma cena à outra: o da substituição das cartas. Todo o resto é diferente.

Poe é um pioneiro adiantando-se um século às discussões dos lógicos do grupo de Carnap sobre a consistência ou a inconsistência das teorias matemáticas. Lacan retoma essas discussões, enriquecidas pela sua leitura dos desafios próprios aos problemas lógicos ligados às lógicas binárias, as únicas, na época, que podiam permitir a invenção de "máquinas pensantes", de onde provieram nossos computadores, e as únicas também a permitir a concepção de lógicas consistentes, ou seja, sem falhas.

As três novelas de Poe tratam do tema da fiabilidade do raciocínio dedutivo do qual demonstram as falhas. Por isso, convém lembrar que Poe expõe sua preferência do jogo de damas em comparação com o jogo de xadrez, pois o primeiro, diz ele, cria uma moldura muito precisa para o raciocínio, enquanto o jogo de xadrez seria mais fantasioso. O jogo de damas obedece a uma lógica binária semelhante àquela proposta por Turing e, em seguida, contestada por Gödel. Turing e Gödel foram alguns dos maiores matemáticos e lógicos do século passado, sobretudo Gödel. Cabe assinalar que, sendo um gênio da lógica, era também completamente louco. Por exemplo, acreditava piamente que a matemática obedecia a regras impostas por anjos responsáveis por este setor do pensamento, enquanto as falhas na teoria matemática eram obra de demônios. Resumo assim, de maneira imprópria. Tal como resumo, pode-se acreditar que Gödel era um cientista religioso, mas a situação era bem pior.

O teorema dos incompletos é uma poderosa defesa de Gödel, no sentido psicanalítico do termo, para escapar à loucura. Por exemplo, as falhas inerentes aos sistemas completos e fechados lhe serviam a evitar uma completa paranoia. Este teorema afirma que todo sistema formulado com um número finito de axiomas é incompleto, o raciocínio sendo concebido como um sistema incompleto. Esse teorema implica outros: por exemplo, o da incapacidade da razão de resolver todos os problemas que se coloca. E mesmo de conceber todos os problemas que existem no universo. Pelo menos durante um tempo de vida limitado. Era isso o que motivava Gödel a acreditar em uma vida após a morte, que levaria enfim à 
compreensão e à resolução de todos os problemas. Assim, a psicanálise freudiana e seu projeto que data de Leibniz, que vê uma razão em tudo e para tudo, dependeria da vida eterna.

Paralelamente a essa noção dos "incompletos", Gödel introduz a noção da "indecisão". A maioria dos problemas sobre os quais podemos raciocinar são indecidíveis. Somente nossa intuição poderá nos orientar, pois nossa razão não pode sozinha nos guiar.

Com base nessas teses, Bárbara Johnson, em 1980, traz uma contribuição de peso às questóes relativas à "Carta roubada". Ela salienta fundamentalmente a importância do quadro de referência teórico e afirma que a leitura de Derrida não é mais verdadeira do que a de Lacan, nem, aliás, mais falsa. Bastaria dizer que qualquer nova análise nunca incidirá sobre os mesmos elementos das análises precedentes, pois que de outra forma não teria sentido. Ou seja, estaríamos no caso do Pierre Mesnard, tradutor de Don Quixote, de Borges, que sonhava com uma tradução tão perfeita que acabou reescrevendo palavra por palavra o livro que deveria ter traduzido.

Johnson (1980) indica a natureza inadequada de qualquer abordagem metodológica baseada em números ou em figuras geométricas quando se trata de análise. Seu argumento essencial é o de que a "última palavra é que não há última palavra”, citando a versão norte-americana do paradoxo de Zenão, tal como Mark Twain o formula: "toda afirmação geral é inútil, inclusive esta”. O paradoxo de Zenão, o eleata, afirmava, lembro, que "todos os cretenses são mentirosos. Ora, eu sou um cretense".

Johnson (1980) salienta ainda a estrutura abissal e assimétrica de qualquer aplicação da análise à própria análise. $\mathrm{O}$ pensamento analítico não tem condições de analisar a si próprio ou, pelo menos, não de forma a dar uma descrição completa, integral e satisfatória de seus procedimentos.

Mas já no ano seguinte, em 1981, um outro autor pilha Johnson (1980) em flagrante delito de contratransferência. Com efeito, seu estudo sobre a discussão de Derrida com Lacan é o terceiro de uma série, o que a coloca, no caso, como um terceiro mediador. Irwin (1986), o autor desse flagrante, constata que, se a "Carta roubada" foi considerada como um exercício lógico apropriado pelos analistas, ela também teve um destino literário e não dos menores, porque José Luiz Borges decidiu retomar, com um século de intervalo, as duas primeiras novelas na trilogia de Poe.

Com efeito, Borges publica El jardin de senderos que se bifurcan, em 1941 (2002), um século após o "Duplo assassinato na Rua Morgue” ([1841] 2004), e "A morte e a bússola", em 1942 (2002), um século após "O mistério de Marie Roget” ([1842] 2003). 
Para a primeira destas novelas é central uma carta muito particular: trata-se de um pergaminho onde está escrito em ideogramas apenas um nome, em caligrafia chinesa. A caligrafia deste nome constitui ao mesmo tempo um mapa do universo, um labirinto e um livro, todos infinitos. É verdade que Borges afirma que as controvérsias filosóficas são centrais nesta novela (na verdade, que "usurpam" a novela), mas isto é verdade em geral, desde sempre. Parece-me difícil assinalar neste conto traços comuns entre Borges e Poe, a menos de termos uma completa confiança no que Borges declarará mais tarde.

Entretanto, é indiscutível que logo nos primeiros parágrafos de "A morte e a bússola" Borges ([1942] 2002) escreve que Erik Lönnrot se considera "um puro lógico, uma espécie de Auguste Dupin”. Neste conto de Borges, trata-se também de cartas, consideradas como índices encontrados no local dos crimes, mas também em sua existência singular, se assim posso dizer, de "letras" (jogo de palavras entre carta e letra, no sentido do alfabeto, e no sentido que a Cabala lhes atribui, isto é, enquanto vetores de mistérios e de significados que as ultrapassam em muito (em francês, ambas as palavras sendo significadas por lettre).

Abenjacán el Bojarí, muerto en su laberinto (Borges, 1951) quebra a temporalidade da lógica dos aniversários seculares dos contos de Poe, estabelecida por Borges, mesmo que seu conto se refira ainda, de forma explícita, à novela de Poe. Dois amigos tentam resolver o problema da morte de Abenjacán el Bojarí. Um deles chama a atenção do outro, alertando-o para não multiplicar os mistérios, ou seja, ser simples e sucinto: "Lembre-se da carta roubada de Poe". E o outro responde que tudo pode também se tornar muito complexo: "Lembremo-nos do universo!".

Borges explica as razões pelas quais quebrou a lógica temporal que havia imposto a si próprio no tocante a Poe. Para ele, o romance policial tinha-se tornado uma caricatura, uma falsificação do que era no passado. Ora, o gênero policial foi considerado como a única alternativa válida para as histórias românticas, o romantismo tomado aqui como um período determinado da história da literatura e da arte. Mas o fato é que em toda verdadeira história romântica, pelo menos no caso do romantismo alemão, sempre há uma morte ou um assassinato.

Irwin (1986), por sua vez, após haver indicado a multiplicidade de referências a Poe feitas por Borges, interpreta que Borges, na verdade, observou a impossibilidade de escolher entre as estruturas ternárias e quaternárias. Na esteira de Bárbara Johnson (1980), Irwin (1986) salienta a natureza insolúvel dos problemas ligados à consciência de si e, por extensão, da autoanálise. Ele menciona o drama específico da letra " $\mathrm{D}$ " nos nossos alfabetos, que, apesar de ser nossa quarta letra, possui raízes gregas que a representam como um triângulo, $\Delta$. Como me 
assinala Thiago, meu filho, em francês, e talvez também em português, o des, ou o "de", é utilizado sempre de maneira a indicar um sentido contrário ao do verbo proposto: desfazer, desligar, desencomendar, desestabilizar, etc.

Irwin (1986) mostra cabalmente que Lacan não apenas lia Borges, mas seguia também à risca suas indicações de leitura, notadamente quando o escritor argentino indica a leitura de John Wilkins, filósofo e linguista inglês que reintroduziu as preocupações e soluções cabalísticas na linguística, em busca do Nome Absoluto, precursor do Nome-do-Pai, tal como Lacan pôde compreendêlo, ao menos em certo momento de suas reflexōes.

Resumo aqui, embora de forma inábil, como qualquer síntese, o texto tão rico e abundante em precisões de Irwin (1986), que conclui indicando a dificuldade de Lacan em admitir a prioridade de Borges na leitura da "Carta roubada", que o inspira, e também a prioridade da ficção para uma disciplina como a psicanálise, que deseja, ou desejava, ser científica, no sentido especial atribuído nos séculos XVIII e XIX à palavra "ciência”, que pressupunha precisão e exatidão, o que nunca tinha sido o caso até então e também deixou de sê-lo. Na Grécia antiga é a filosofia que é considerada como ciência e, em seguida, a religião passa a ser considerada como única ciência, antes que a matemática ou domínios conexos, capazes de serem formulados em linguagem matemática, lhes roubem o lugar. No século XX, já Gödel considera a psicanálise como fundamento de toda ciência.

Irwin (1986) tem muitas razōes. Quando digo que Lacan nunca foi um exegeta, quero também dizer que ele se limita a fazer alusōes às fontes de suas teses, no melhor dos casos, indicando-as raramente de maneira explícita.

\section{ECOS FRANCESES}

Milner (1985), no seu trabalho "Retorno à Carta roubada", retoma a preocupação de Irwin (1986) sobre a importância da letra “D” e das cartas no conto de Poe. Nessa novela há com efeito um certo número de cartas em circulação e não apenas a carta, é claro, que a Rainha lê. Existe também a carta que o Ministro D. utiliza para substituí-la, a carta que serve para que Dupin recupere, na casa do Ministro, a carta roubada, lançando mão para isto de quase o mesmo procedimento utilizado pelo Ministro anteriormente, ou seja, substituindo-a por uma outra carta, e, finalmente, a carta que encerra o caso, e com a qual o Chefe de Polícia agradece Dupin pela sua diligência, ou seja, o cheque com o qual o recompensa pela recuperação da carta roubada; logo, que a retoma.

As cartas, na época, não tinham a forma que as de hoje têm. Não havia uma carta e um envelope, a carta sendo colocada no envelope. As cartas eram formadas 
por folhas grandes que se dobravam e se desdobravam, até que na sua parte mais interior fossem escritas e que, na parte mais externa, fosse colocado o nome do destinatário. Da mesma forma como existem quatro cartas no conto, os folhetos que as constituíam eram dobrados quatro vezes. De uma carta para outra ocorria uma duplicação, tanto para as cartas em circulação no conto quanto para os folhetos que as constituíam. De sorte que, observo, é possível que estruturas binárias, ternárias e quaternárias se articulem e se ocultem mutuamente, nunca sendo exaustivas.

Mas Milner (1985) muda de registro para indicar uma outra coisa: a inicial comum ao Ministro D. e a Dupin. Ele esquece a indicação feita por Irwin (1986), de que Poe diz que Dupin morava na Rua Dénôt. Entretanto, Milner mostra, com o auxílio dos fatos da época em que Poe escreveu seu conto, que Dupin e o Ministro D. são irmãos e que é a rivalidade entre irmãos que justifica o texto que Dupin escreve na carta que deixa na lareira da sala do Ministro e que vem substituir a carta da Rainha. Este texto é:

Um destino tão funesto

Se não for digno de Atreu, é digno de Tiestes ${ }^{1}$.

Esses versos de Crébillon, dramaturgo francês inspirado pela mitologia, se referem à tragédia grega. Atreu e Tiestes, dois irmãos, brigavam sempre. Atreu mata seus sobrinhos e sobrinhas, filhos e filhas de Tiestes, os cozinha e os oferece a Tiestes numa refeição, antes de apresentar-lhe suas cabeças ensanguentadas.

Derrida ([1975] 1987) já havia assinalado que essas linhas haviam sido mencionadas três vezes na obra de Lacan e que, em duas delas, o Doutor, como o chama Milner (1985), comete um lapso, substituindo "desígnio" por "destino".

Milner (1985) retoma observações que Lacan não levara em consideração. $\mathrm{O}$ Doutor se limitara à novela de Poe enquanto pretexto para suas teses. Milner retoma esse fio da realidade da lógica, mas o enriquece com várias perspectivas. Primeiro, toma em consideração a realidade sociopolítica da época em que Poe escreve, mostrando o que eram efetivamente as práticas policiais francesas; a seguir Milner retoma a perspectiva da realidade literária já que dois "dês", as iniciais do nome do Ministro e de Dupin, encontram-se também nos versos de Mallarmé (1914), Un coup de dés jamais n'abolira le hasard (Um lance de dados jamais abolirá o acaso) (dé em francês significa tanto um dado, quanto a letra "D”, lembro). Este poema sugere que nenhuma lógica conseguirá resolver realidades que não sejam da ordem da lógica, mas de outra ordem. 
Compreenda-se: quando lançamos dados, temos um número finito de possibilidades de resultados, estatisticamente distribuídos. O jogo de dados é apenas uma versão mais ampla do jogo do par ou ímpar, ou do jogo de cara ou coroa. Mas e se os resultados não corresponderem às estatísticas, como o havia sugerido Lacan? Temos aqui a versão desenvolvida por Tom Stoppard em Rosencrantz e Guildenstern estão mortos (1966), uma outra versão de Hamlet, peça em que várias cartas se situam em momentos cruciais do drama. No jogo de cara e coroa, do "Ser ou não ser", desde que a questão se coloca, irremediavelmente, a moeda cai em coroa: ser. $\mathrm{O}$ que modifica todos os resultados estatísticos. Lacan se concentra sobre a passagem "Ser ou não...", "ser ou não...", ou não, o quê?

Observo que não são apenas os irmãos que têm o mesmo nome: isto ocorre também com pais e filhos. Se entre Atreu e Tiestes reina uma rivalidade fraternal, Crébillon pai, autor das linhas citadas por Poe e repetidas por Lacan, rivaliza em escrita com seu filho, também Crébillon. A rivalidade entre pai e filho cria problemas diferentes dos da rivalidade entre irmãos.

Uma última contribuição às discussões sobre "A carta roubada" é o texto de René Major (1987), "A parábola da carta roubada: da direção da cura e de seu relato".

Como Poe escreveu três contos policiais, e como Borges retomou esse processo, escrevendo por sua vez três outras novelas, a perspicácia de Major (1987) o leva a constatar que Lacan escreveu três textos maiores sobre a dinâmica da cura analítica. Utilizo essa expressão para evitar aquela mais clássica de técnica analítica. Pois, de maneira bastante ampla, a experiência a mostra como ilusória. As observações de abertura do texto de Major afirmam: "A cura, diz-se, dirige-se a si própria. Quando pensamos que a estamos dirigindo, é ela, imagina-se, que nos dirige. E quando ela dirige, supomos que ela se dirige. Onde vai a cura que se dirige, se é que se dirige mais do que se deixar levar pela in-direção?" (Major, 1987: 81).

Os três textos de Lacan analisados por Major (1987) são: "Função e campo da palavra e da linguagem em psicanálise", de 1953; "O seminário sobre a 'Carta roubada", de 1955, e "A instância da letra no inconsciente ou a razão desde Freud (ou segundo Freud)", de 1957. Para fazê-lo, Major se baseia na leitura de três textos que não estudei aqui, embora tratem da "Carta roubada". São eles, de Derrida, "Freud e a cena da escrita", publicado em seu livro L'écriture et la différence ( $A$ escritura e a diferença), de 1967; de Jean-Luc Nancy e Phillippe Lacoue-Labarthe, de 1973, Le titre de la lettre (O título da carta ou da letra); e, enfim, de Descombes, "À l'enseigne du signifiant émancipé (Sob a marca do significante emancipado)", em seu livro de 1983, Grammaire d'objets en tout genre (Gramática de objetos de todo gênero). 
Como podemos observar, deixei de lado esses três textos, por razões que já sugeri. Da mesma maneira que Poe é na verdade um pretexto para Lacan, e Lacan por sua vez é um pretexto para Derrida, e para os outros, esses outros servem de pretexto para René Major (1987). Observo ainda que os ecos franceses na verdade precedem seus rumores americanos e com eles se misturam, som original e ecos confundidos, em incessante vai-e-vem, contrariamente ao que pretende Major. O original seria Poe e não Lacan. Ou Poe descoberto e traduzido por Baudelaire. Originais e traduçôes tendem sempre a confundir-se, o melhor exemplo disto sendo a Bíblia.

Não mencionei esses textos por vários motivos. O primeiro é que, de forma intuitiva, pelo que já mencionei de Gödel, por mais longe que possamos ir, nossa leitura permanecerá incompleta e o texto permanecerá um pretexto. O segundo é que me parece que Major (1987) salienta um ponto essencial, mas não o explora, e que será sempre assim. Esse ponto é a rivalidade existente entre Lacan e Marie Bonaparte. Major cita longamente uma carta de Lacan a Loewenstein, seu antigo analista e amigo íntimo de Marie Bonaparte, na qual Lacan dá mostras, com relação a esta última, de uma verdadeira rivalidade especular. Essa carta permite que Major reescreva o Esquema L, colocando em cada uma de suas extremidades inicialmente o Rei, a Rainha, o Ministro e Dupin, e depois, Freud, Bonaparte, Nacht e Lacan.

No esquema L, vale lembrar, Lacan colocava nas extremidades $S$, a, a' e o A. Assim:

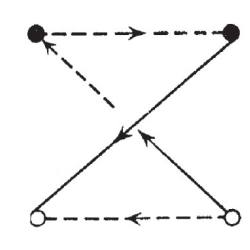

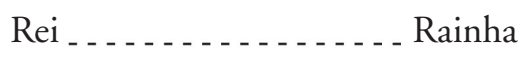

Chefe de Polícia

Ministro ------------Dupin

E, depois,

Freud . . . . . . . . . . . . Bonaparte

Lœwenstein

Nacht Lacan 
Trata-se, com efeito, de algo astucioso e surpreendente. Resta-nos saber se Major (1987) estaria atribuindo ao Chefe de Polícia e a Lœwenstein o papel de fatores do inconsciente. No que diz respeito a este último, é provável, e a cegueira de Lacan na sua relação especular com Marie Bonaparte, queixando-se dela e acusando-a junto a Lœwenstein, amigo íntimo da Princesa, é surpreendente.

Uma das últimas palavras sobre seus próprios contos deve voltar a Poe. Em epígrafe do "Duplo assassinato na Rua Morgue", Poe atribui a Sir Thomas Browne estas palavras: "O que cantavam as Sereias? Qual era o nome de Aquiles quando se escondia entre mulheres? - questões embaraçosas, é verdade, mas que não escapam a toda conjectura" (Poe, [1841] 2004: 47).

Talvez. Por minha parte, assinalo que a Morgue, nome de rua inventado por Poe, é o local onde se recolhem os cadáveres. Como se o duplo assassinato que abre a série dos três contos houvesse ocorrido no mesmo lugar onde estão os cadáveres. Cortazar, porém, que faz o prefácio das Histórias extraordinárias de Poe ([s/d] 2004) em francês, assinala o romantismo deste autor.

\section{ELEMENTOS DE PSICANÁLISE}

Parece surpreendente que tantos analistas e tantas análises tenham deixado de lado alguns fatores importantes, bastante empíricos e bastante filosóficos, e absolutamente pessoais, ao mesmo tempo.

Primeiro, os dados empíricos:

1 - Lacan foi analisado por Lowenstein, a quem mais tarde escreve para reclamar da Princesa. Lacan interrompeu sua análise de forma abrupta;

2 -Marie Bonaparte, além de seu interesse por Poe, tomou posse de cartas que Freud não queria divulgar. De um ponto de vista comercial, as comprou, mas, visto de outro ângulo, talvez tenha se apoderado delas, ou pelo menos tomado de empréstimo a Freud em todos os sentidos que poderíamos dar a essas palavras. Lembremo-nos de que o título da novela de Poe, em inglês, é The purloined letter e não The stolen letter. "Roubada" foi a tradução que Baudelaire encontrou para traduzir "purloined". "Roubada" é um dos sentidos de "purloined”, mas não o primeiro;

3 - Marie Bonaparte, na sua juventude, apaixonou-se por um homem a quem escrevia cartas cheias de paixão. Esse homem, que parecia inicialmente um príncipe encantado, revelou-se na verdade um escroque e utilizou as cartas da jovem princesa para fins de chantagem, ameaçando torná-las públicas, o que mancharia o nome da família real grega. Marie teve de confessar esse problema a seu pai, que encarregou a polícia e detetives privados de retomar posse das cartas, o que foi feito mas custou caro; 
4 - As cartas de Freud de que ela se apoderou eram a tal ponto um caso de roubo que Anna Freud nunca quis autorizar sua publicação integral;

5 - Um outro jovem, igualmente sedutor, insinuou-se junto a Anna Freud e tornou-se de tal maneira indispensável que ela lhe permitiu o acesso aos arquivos de seu pai, onde figuravam os originais dessas cartas;

6 - Esse jovem, Jeffrey Moussaieff Masson, "tomou-as emprestadas" ou "roubou-as”, para finalmente trazê-las integralmente a público. São as célebres cartas a Fliess, um dos monumentos inaugurais da psicanálise. Adquirindo certa celebridade, Jeffrey Masson conseguiu publicar Attacks on truth (Ataques contra a verdade), traduzido para o francês como Le réel escamoté ( $O$ real escamoteado), em que denuncia a "covardia" de Freud ao abandonar a "teoria da sedução".

Lembro enfim os dados filosóficos: a discussão sobre as origens ou as estruturas ternárias ou quaternárias do espírito humano não datam nem de Poe, nem dos psicanalistas, mas são dados constantes desde sempre de todo pensamento. Já os primeiros filósofos gregos oscilavam entre teses que atribuíam as origens do universo a dois elementos, o oceano e a terra; ou a 2+1, a noite, o vento e Eros; ou ainda a 1+1+1, o Caos, a Terra e o Céu; e, enfim, os quatro elementos fundamentais e simultâneos: água, fogo, ar e terra. Estes quatro elementos se tornarão um só, o infinito, que, por sua vez, será decomposto em átomos. Estas "estruturas" estão também presentes em todas as religiões.

Mas isto já é uma outra história. Permanece entretanto o fato de que uma das lendas fundadoras da psicanálise é uma espécie de romance policial em que um Rei busca um assassino sem perceber que ele próprio é esse assassino. É um tema digno de Borges. Essa história contada por Freud é também um pretexto, pois ele modifica o original. $\mathrm{Na}$ lenda grega, o assassino na verdade se vinga de uma tentativa de morte da qual foi vítima. Com efeito, já o sabemos hoje, Laio e mesmo Jocasta tentam matar Édipo antes que este venha a se vingar, os pais tentam matar os filhos, antes que estes se vinguem.

Termino lendo um trecho de Karl Marx ([1867] 1974):

O filósofo produz ideias, o poeta poemas, o eclesiástico sermões, o professor tratados. [...] O criminoso produz crimes. Se examinarmos mais de perto as relaçôes que existem entre esse último ramo de produção e a sociedade no seu conjunto, abandonaremos uma série de preconceitos. O criminoso não produz apenas crimes: é ele que produz o direito penal e portanto o professor de direito penal e, com este, o inevitável tratado no qual o professor registra seus cursos para colocá-los no mercado como "mercadoria". Resulta daí um aumento da riqueza nacional. [...] E mais: o criminoso produz ainda todo o aparelho policial e judiciário: guardas, juízes, carrascos, jurados, etc e todas essas atividades 
diversas, que constituem outras tantas categorias de divisão social do trabalho, desenvolvem diferentes categorias do espírito humano e criam, ao mesmo tempo, novas necessidades e novas formas de satisfazer essas necessidades. [...] $\mathrm{O}$ criminoso cria uma sensação de que tem ao mesmo tempo algo da moral e do trágico e, assim fazendo, fornece um "serviço", mexendo com os sentimentos morais e estéticos do público. [...] Produz também arte, belas-letras, e até mesmo tragédias. [...] Ao mesmo tempo que o crime retira do mercado de trabalho uma parte do excesso da população e que reduz assim a concorrência entre os trabalhadores, contribuindo para impedir os salários de cair abaixo do mínimo, a luta contra a criminalidade absorve uma outra parte dessa mesma população. O criminoso, portanto, realiza uma dessas "compensações naturais" que criam equilíbrio e suscitam uma multiplicidade de trabalhos "úteis".

Pode-se demonstrar de forma detalhada a influência que o criminoso exerce no desenvolvimento da força produtiva: as fechaduras teriam chegado a esse tipo de perfeição se não existissem ladrões? Se não houvesse falsários, teriam as notas bancárias atingido essa precisão? O microscópio teria entrado nas esferas comerciais se não existissem fraudes? A química aplicada não deve tanto à falsificação e à repressão desta os esforços legítimos para melhorar a produção? Ao buscar e encontrar incessantemente meios de atacar a propriedade, o crime cria em permanência novos meios para sua defesa, de tal forma que ele dá à mecanização um impulso tão produtivo quanto aquele que resulta das greves. No campo do crime privado, o mercado mundial teria nascido sem os crimes nacionais? E as próprias nações? E desde Adão a árvore do pecado não é ao mesmo tempo a árvore da ciência? (Marx, [1867] 1974: 7-14).

Os psicanalistas têm todo interesse em meditar sobre este fato: que toda lei traz embutida sua transgressão e toda ciência sua falha, como todo paraíso, seu pecado. Os cientistas sociais descobririam também que a corrupção não é um problema moral, mas um fato social, uma forma rápida de ascensão social. Como diria Brecht: que crime comete quem rouba bancos comparado aos crimes que cometem os banqueiros?

Termino aqui.

\section{REFERÊNCIAS BIBLIOGRÁFICAS}

Borges, J. L. (1951). Abenjacán el Bojarí, muerto en su laberinto. Buenos Aires: Editorial Sur. (2002). Ficciones. Madrid: Alianza Editorial. 
Derrida, J. (1975/1987). Le facteur de la vérité. Em The postcard: from Socrates to Freud and beyond (pp. 412-496). Chicago and London: University of Chicago Press.

Freud, S. (1911a/1969). Notas psicanalíticas sobre um relato autobiográfico de um caso de paranoia (Dementia Paranoides). Obras completas, ESB, v. XII. Rio de Janeiro: Imago.

- (1911b/1969). Grande é a Diana dos Efésios. Obras completas, ESB, v. XII. Rio de Janeiro: Imago.

- (1931/1969). A sexualidade feminina. Obras completas, ESB, v. XXI. Rio de Janeiro: Imago.

Guignard. P. (1996). Le sexe et l'effroi. Paris: Gallimard.

Irwin, J. T. (1986). The mysteries to a solution: Poe, Borges and the analytic detective story. Baltimore: Johns Hopkins University Press.

Johnson, B. (1980). The critical difference. Baltimore: Johns Hopkins University Press.

Lacan, J. (1949/1966). Écrits. Paris: Seuil.

Major, R. (1987). La parabole de la lettre volée: de la direction de la cure et de son récit. Études freudiennes, 30, 81-130.

Mallarmé, S. (1914). Un coup de dés jamais n'abolira le hasard. Disponível em <http:// www.direz.org/site/uploads/Mallarme/Coupde.pdf>. Acessado em 27/7/2008.

Marx, K. (1867/1974). Le capital. Em Théories sur la plus value. Paris: Editions Sociales.

Milner, J.-C. (1985). Retour à La lettre volée. Em Détections fictives (pp. 9-44). Paris: Seuil.

Poe, E. A. (s/d/2004). Histoires extraordinaires. Paris: Gallimard. . (1842/2003). Histoires grotesques et sérieuses. Paris: Gallimard.

Richard, C. (2007). Poe (Edgar Allan), 1809-1849. Encyclopédie Universalis. Disponível em <http://www.universalis.fr/>. Acessado em 27/7/2008.

\section{NoTAS}

1 Versos de Prosper Jolyot de Crébillon, dito Crébillon pai, Atrée et Thyeste (Ato 5) (1707), Epígrafe de Un destin si funeste, F. Roustang, Paris, Minuit, 1976.

Recebido em 15 de maio de 2008 Aceito para publicação em 27 de julho de 2008 